\title{
Superior Hemorrhoidal Artery
}

National Cancer Institute

\section{Source}

National Cancer Institute. Superior Hemorrhoidal Artery. NCI Thesaurus. Code C33677.

The continuation of the inferior mesenteric artery with two branches that descend down either side of the rectum and anastomose with the middle and inferior hemorrhoidal arteries. 